\title{
ESTUDO SOBRE O CONCEITO DE COMPROMETIMENTO E COMPROMETIMENTO EXCESSIVO NO MUNDO DO TRABALHO
}

\author{
Bianca Saionara Lima Pessôa ${ }^{1}$; Paulo Wenderson Teixeira Moraes ${ }^{2}$ \\ 1. Bolsista PIBIC/CNPq, Graduando em Psicologia, Universidade Estadual de Feira de Santana, e-mail: \\ biaslp@hotmail.com \\ 2. Orientador, Departamento de Ciências Humanas e Filosofia, Universidade Estadual de Feira de Santana, e-mail: \\ pwmoraes@yahoo.com.br \\ 3. Participante do projeto ou núcleo tal, Departamento de Nome, Universidade Estadual de Feira de Santana, e-mail:
}

\begin{abstract}
PALAVRAS-CHAVE: Comprometimento com a carreira; Comprometimento excessivo com a carreira; Revisão.
\end{abstract}

\section{INTRODUÇÃO}

Nas sociedades capitalistas a competitividade no trabalho mostra-se como demarcadora das relações, ocupando um lugar central na vida de seus membros (Cooper; Baliglioni Jr, 1988 apud Vasconcelos; Guimarães, 2009). A saúde do trabalhador fica ameaçada quando a competição se torna predatória, pois o nível insuportável de estresse leva a fadiga e ao desgaste profissional (Silva, 2010). Nesse contexto, a carreira torna-se um desafio para o trabalhador, pois além dos esforços exigidos para melhorar a qualificação e conquistar uma boa posição no emprego, ele precisa aprender a lidar com situações potencialmente estressantes (Vasconcelos e Guimarães, 2009).

O comprometimento com a carreira tem se mostrado como uma forma em que o trabalhador tem encontrado para saber lidar com as adversidades do mundo laboral, investindo e dedicando-se a este percurso de forma saudável. Já o comprometimento excessivo é uma atitude frente à carreira devido a falta de alternativas disponíveis ao trabalhador, o que pode gerar impactos pessoais, organizacionais e sociais expressivos (Rowe e Bastos, 2008). Por isso, estudar e analisar formas saudáveis de comprometimento organizacional, as quais minimizem fatores estressantes a ele, é essencial para desenvolver no mundo do trabalho, uma melhor qualidade de vida, preservando também a saúde do trabalhador.

\section{MATERIAL E MÉTODOS OU METODOLOGIA (ou equivalente)}

Foram considerados dados já existentes no Projeto de Pesquisa " $\mathrm{O}$ mundo do Trabalho na Contemporaneidade e o sofrimento psíquico: o entrincheiramento no trabalho e as LER/DORT entre bancários da Bahia" do autor Moraes (2014). Da citada pesquisa já existente, foram retirados os dados referentes a estresse, comprometimento com a carreira e comprometimento excessivo com a carreira, os quais foram analisados por meio do programa estatístico (SPSS- Statistical Packcage for Social Science, versão 17.0), sendo apresentadas análises de correlação e regressão. Em seguida, as informações foram sistematizadas em tabelas e gráficos com auxílio do Programa Excel da Microsoft Corporation, seguindo a sequência e distribuição das variáveis do estudo, para apresentação das informações obtidas. 


\section{RESULTADOS E/OU DISCUSSÃO (ou Análise e discussão dos resultados)}

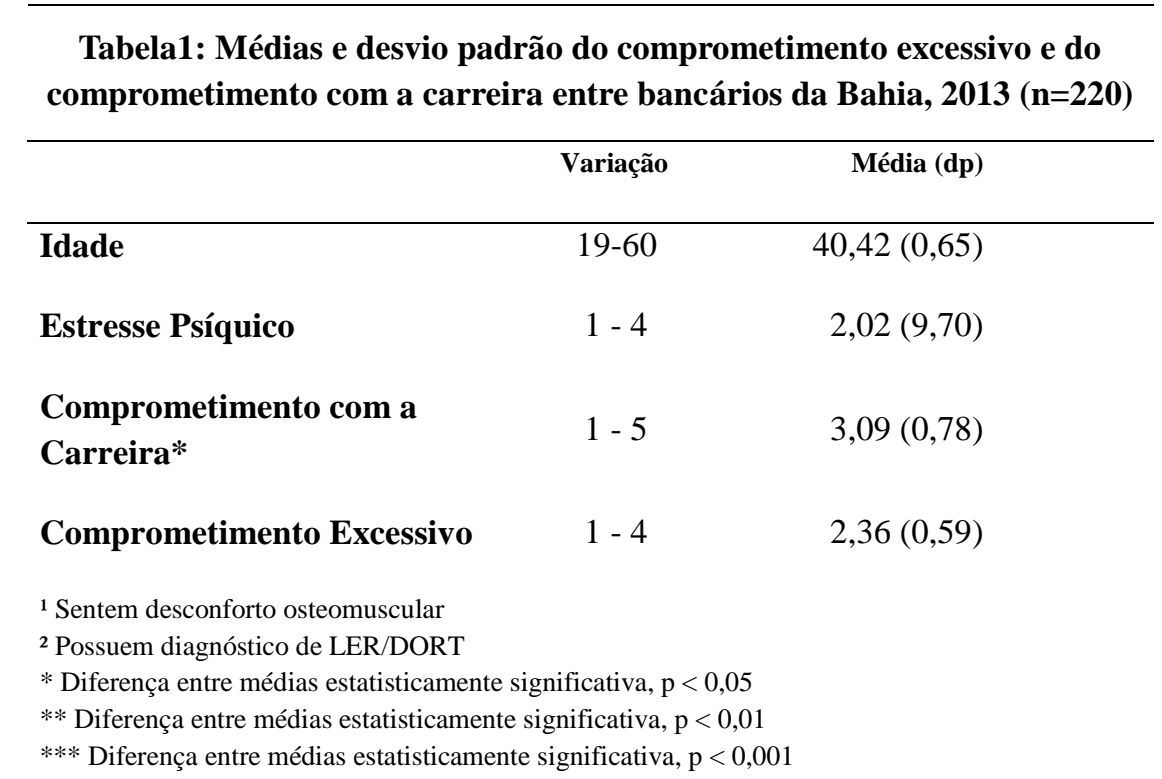

Na tabela 1 destaca-se que, a variável "comprometimento com a carreira" dentro da possibilidade de variação de 1 a 5, apresentou o valor médio de 3,09. Valor este que, se aproxima do significado semântico atribuído ao valor 03 da escala, a saber: "a frase é parcialmente verdadeira a seu respeito". O que indica que, há uma leve tendência ao comprometimento com a carreira, pois os trabalhadores avaliaram positivamente tal resposta, que tem haver com os fatores: identificação, planejamento e resiliência, os quais compõem comprometimento com a carreira.

Tabela 2: Correlações entre idade, sexo, comprometimento com a carreira e comprometimento excessivo com o trabalho, Bahia, 2013, $\mathrm{n}=220$.

\begin{tabular}{l|ccccc} 
& 1 & 2 & 3 & 4 & 5 \\
\hline 1. Idade & 1 & & & & \\
2. Sexo &, 031 & 1 & & & \\
3. Comprometimento Excessivo c/ trabalho &, 096 &, 027 & 1 & & \\
4. Comprometimento com a carreira &,$- 182 * *$ &,- 086 &,$- 182 * *$ & 1 & \\
5. Estresse psíquico &, 101 &, $201 * * *$ &, $493 * * *$ &,$- 407 * * *$ & 1 \\
\hline$* \mathrm{p}<0,05$ & & & & & \\
$* * \mathrm{p}<0,01$ & & & & & \\
$* * * \mathrm{p}<0,001$ standard &
\end{tabular}

Relacionaram-se de forma significativa e inversamente proporcional também, as variáveis, comprometimento com a carreira e comprometimento excessivo, o que condiz com o que a literatura diz, pois estar comprometido com a carreira e estar comprometido excessivamente com o trabalho são posturas diferentes, uma vez que o último direciona-se no sentido positivo, de dedicar-se para a carreira e o outro se direciona no sentido prejudicial para o trabalhador, de estar comprometido em excesso com o trabalho a ponto de comprometer a saúde, como sugere o estudo de Scheible, Bastos \& Rodrigues (2013). 
Tabela 3: Modelos de regressão linear do estresse psíquico em função comprometimento excessivo com o trabalho e comprometimento com a carreira, entre bancários da Bahia, 2013. (n=220)

\begin{tabular}{|c|c|c|c|c|c|c|c|c|}
\hline & $\mathrm{F}$ & $\mathrm{R}^{2}$ & $\Delta \mathrm{R}^{2}$ & B & EP & B & $\mathrm{r}$ & r parcial \\
\hline MODELO 1 & $5,621 * *$ &, 049 &, $049 * *$ & & & & & \\
\hline Idade & & & & ,006 & ,004 & ,095 & ,101 & ,097 \\
\hline Sexo & & & & ,261 & ,087 &, $198 * *$ & ,201 & , 199 \\
\hline MODELO 2 & $28,013 * * *$ & ,280 &, $231 * * *$ & & & & & \\
\hline Idade & & & & ,003 & ,004 & ,049 & ,101 &, 057 \\
\hline Sexo & & & & ,246 & ,076 &, $186 * * *$ & ,201 &, 214 \\
\hline Comp. Exc. C/ Trab. & & & &, 543 &, 065 &, $483 * * *$ & ,493 & ,493 \\
\hline MODELO 3 & $31,939 * * *$ & ,373 &, $093 * * *$ & & & & & \\
\hline Idade & & & & ,002 & ,004 &, 028 &, 101 &, 035 \\
\hline Sexo & & & & ,209 & ,072 &, $158 * *$ & ,201 & , 195 \\
\hline Comp. Exc. c/ Trab. & & & & ,483 & ,062 &, $429 * * *$ & ,493 & ,469 \\
\hline Comp. c/ a Carreira & & & &,- 263 & ,047 &,$- 312 * * *$ &,- 407 &,- 359 \\
\hline \multicolumn{9}{|l|}{$* \quad \mathrm{p}<0,05$} \\
\hline$* * \quad \mathrm{p}<0,01$ & & & & & & & & \\
\hline$* * * \mathrm{p}<0,001$ & & & & & & & & \\
\hline
\end{tabular}

Na tabela 03 de regressão linear, são apresentados três modelos que tentam explicar a variável estresse psíquico. Nota-se que, o primeiro modelo explicou cerca de 4,9\% da variância estresse psíquico. O segundo modelo, o qual foi acrescentado a variável comprometimento excessivo com o trabalho, explica 2,3\% da variância do estresse psíquico, sendo que as variáveis significativas de tal modelo foram sexo e comprometimento excessivo com o trabalho, somando-se o total de $2,8 \%$.

\section{CONSIDERAÇÕES FINAIS (ou Conclusão)}

Portanto, os estudos indicam que, a definição de comprometimento com a carreira aponta para: o padrão de experiências relacionadas ao trabalho de um indivíduo por toda a sua vida. Percebe-se que a conceituação de Carson e Bedeian (1994) engloba melhor os aspectos dos outros conceitos. Para eles, o comprometimento com a carreira é a motivação para trabalhar em uma vocação escolhida, dividindo-o em três componentes: identidade com a carreira, que representa o vínculo emocional; planejamento da carreira, que determina as necessidades de desenvolvimento na carreira bem como objetivos; e resiliência na carreira, que remete à constância na carreira mesmo em face das adversidades.

Já em relação ao comprometimento excessivo, não há ainda um consenso na literatura, porém a definição que melhor explica é a que foi abordada por Scheible, Bastos e Rodrigues (2013), a qual remete à continuidade de profissionais em uma carreira, pois mudar lhes parece desvantajoso. Para Carson, Carson e Bedeian (1995), tem haver com um processo de estagnação no qual os indivíduos não se adaptam e não se motivam a encontrar alternativas para seu encaminhamento profissional. Adicionam, ainda, que alguns sintomas do entrincheiramento podem ser: medo de estigma social, 
visão da idade como fator de limitação das alternativas de carreira, percepção de desequilíbrio na relação custo-benefício da mudança.

Portanto, ressalta-se a importância de profissionais especializados que possam estar acompanhando mais de perto estes trabalhadores, identificando seus objetivos, suas motivações e medos, quais fatores no clima da organização podem estar contribuindo para gerar possíveis problemas, avaliando a qualidade de vida laboral, com o intuito de poder intervir nas organizações, realizando, por exemplo, orientações de carreira, atividades que diminuam o estresse, terapia de grupo no trabalho, pesquisas de clima, incentivando também de forma geral, a melhora nas relações interpessoais da organização.

\section{REFERÊNCIAS}

ANJOS, Gilney Christierny Barros Dos. Comprometimento organizacional e com a carreira/profissão: um estudo de caso em uma organização do Terceiro Setor. Área temática: Recursos Humanos, Universidade Federal de Campina Grande, 2011. CARSON, K. D., CARSON, P. P., \& BEDEIAN, A. G. Development and construct validation of a career entrenchment measure. Journal of Occupational and Organizational Psychology, 68, 301-320, 1995.

MORAES, Paulo Wenderson Teixeira. O Efeito dos Fatores Psicossociais e dos Vínculos com a Carreira nos Sintomas de LER/DORT entre Bancários da Bahia, UFBA, Salvador, Bahia, 2014.

OLIVEIRA, Paloma Lago Marques de, BARDAGI, Marúcia Patta. Estresse e comprometimento com a carreira em policiais militares. Bol. Psico., vol.59 no.131, São Paulo dez., 2009.

RAIMUNDO, Emília Regina Cabral. A Globalização e seus impactos sobre o mercado de trabalho brasileiro na década de 1990, Universidade Federal de Santa Catarina, Curso de Graduação em Ciências Econômicas, 2007.

ROWE, Diva Ester Okazaki, BASTOS, Antonio Virgilio Bittencourt. Comprometimento ou entrincheiramento na carreira? Um estudo entre docentes do ensino superior, XXXII Encontro da ANPAD, Rio de Janeiro, 2008.

SCHEIBLE, Alba Couto Falcão, BASTOS, Antonio Virgilio Bittencourt, RODRIGUES, Ana Carolina de Seleghim MR, Mombelli MA, Oliveira MLF, Waidman MAP, Marcon SS. Sintomas de estresse em trabalhadoras de enfermagem de uma unidade de pronto socorro. Revista Gaúcha Enfermagem, 2012.

SILVA, Juliana Fernandes da Costa, Estresse Ocupacional e suas Principais causas e consequências, Universidade Cândido Mendes Instituto a Vez do Mestre, Rio de Janeiro, 2010.

VASCONCELOS, Eveli Freire, GUIMARÃES, Liliana A. M., Esforço e Recompensa no trabalho de uma amostra de profissionais de enfermagem, Instituto Metodista de Ensino Superior: Copyright, 2009. 